\title{
A case in which a capnometer was useful for diagnosing laryngospasm following administration of sugammadex
}

\author{
Keito Kou, Takeshi Omae ${ }^{*}$, Saiko Wakabayashi and Sonoko Sakuraba
}

\begin{abstract}
Background: Sugammadex has been reported to cause upper-airway obstruction, such as laryngospasm or bronchospasm. These two conditions are treated using different approaches, but the differential diagnosis is difficult.

Case presentation: We describe a case in which general anesthesia was administered via endotracheal intubation, in combination with brachial-plexus block, for arthroscopic surgical treatment of a rotator-cuff tear caused by recurrent shoulder dislocation. The total dose of rocuronium administered was $90 \mathrm{mg}$, and the last dose of $10 \mathrm{mg}$ was given $15 \mathrm{~min}$ before the end of the surgery. Sugammadex was intravenously administered at $100 \mathrm{mg}$ to reverse the effect of rocuronium after the operation ended. After extubation in this case, we placed a mask firmly around the patient's mouth, and thus, there was no air leakage around the mask. We detected upper-airway obstruction that was presumably attributable to administration of sugammadex. The end-tidal carbon dioxide $\left(\mathrm{EtCO}_{2}\right)$ concentration was undetectable on a capnometer. Although $100 \%$ oxygen was administered at $10 \mathrm{~L} / \mathrm{min}$ via a facemask, oxygen saturation $\left(\mathrm{SpO}_{2}\right)$ decreased to approximately $70 \%$. With suspected onset of laryngospasm, continuous positive airway pressure with 100\% oxygen at $10 \mathrm{~L} / \mathrm{min}$ was started at $30 \mathrm{~cm} \mathrm{H}_{2} \mathrm{O}$. The patient's airway obstruction resolved after a short time.
\end{abstract}

Conclusion: The use of a capnometer facilitated the diagnosis of laryngospasm and allowed us to administer appropriate treatment after administration of sugammadex.

Keywords: Capnometer, Rocuronium, Sugammadex, Continuous positive airway pressure, Bronchospasm

\section{Background}

Sugammadex, an antagonist of muscle relaxants, has been reported to cause upper airway obstruction, such as laryngospasm [1-3] or bronchospasm [3, 4]. We herein report our experience with a case in which a capnometer was useful for the differential diagnosis of upper airway obstruction following administration of sugammadex.

\section{Case presentation}

A 25-year-old man with a height of $168 \mathrm{~cm}$ and weight of $68 \mathrm{~kg}$ underwent arthroscopic surgery to treat a rotator cuff tear caused by recurrent shoulder dislocation. He had no remarkable medical history. General anesthesia was induced with propofol $(100 \mathrm{mg})$, remifentanil $(0.3 \mu \mathrm{g} /$ $\mathrm{kg} / \mathrm{min}$ ), and rocuronium $(40 \mathrm{mg})$, while an $8.0-\mathrm{mm}$

* Correspondence: omae@za2.so-net.ne.jp

Department of Anesthesiology and Pain Clinic, Juntendo University Shizuoka hospital, 1129 Izunokuni, Shizuoka, Japan endotracheal tube was inserted for airway management. Additionally, a brachial plexus block was administered with $0.25 \%$ levobupivacaine $(30 \mathrm{~mL})$ through an interscalene approach under ultrasonographic guidance, and an indwelling catheter was placed. While the patient was placed in the beach-chair position during surgery, anesthesia was maintained with oxygen $1 \mathrm{~L} / \mathrm{min}$, air $2 \mathrm{~L} / \mathrm{min}, 1.5 \%$ sevoflurane, and remifentanil $0.2-0.3 \mu \mathrm{g} /$ $\mathrm{kg} / \mathrm{min}$. The patient was monitored using five-lead electrocardiography, pulse oximetry, and capnometry. The total dose of rocuronium administered was $90 \mathrm{mg}$, and the last dose of $10 \mathrm{mg}$ was given $15 \mathrm{~min}$ before the end of the surgery. The operative time was $3 \mathrm{~h}$ and $21 \mathrm{~min}$. Continuous infusion of remifentanil was discontinued simultaneous with the end of surgery. Administration of sevoflurane was discontinued 5 min later. Sugammadex was intravenously administered at $100 \mathrm{mg}$ to reverse rocuronium. Since the patient regained clear consciousness and spontaneous breathing at $10 \mathrm{~mL} / \mathrm{kg}$, 
the intubation tube was removed. Immediately after extubation, he presented with retractive breathing and stridor. According to the capnometer readings, the end-tidal carbon dioxide $\left(\mathrm{EtCO}_{2}\right)$ concentration was undetectable. Although 100\% oxygen was administered at $10 \mathrm{~L} / \mathrm{min}$ via a facemask, oxygen saturation $\left(\mathrm{SpO}_{2}\right)$ decreased to approximately 70\%. Onset of laryngospasm was suspected, and thus, $100 \%$ oxygen was started at $10 \mathrm{~L} / \mathrm{min}$ with continuous positive airway pressure $\left(30 \mathrm{~cm} \mathrm{H}_{2} \mathrm{O}\right)$. The patient's airway was reopened after a while. Consequently, both stridor and retractive breathing resolved. The $\mathrm{EtCO}_{2}$ waveforms became detectable with a capnometer, and $\mathrm{SpO}_{2}$ also improved to $100 \%$ (Fig.1). The patient was monitored in the operating room for $30 \mathrm{~min}$. After a stable level of consciousness and stable respiratory patterns were confirmed, he was discharged from the operating room. No recurrence of laryngospasm was observed throughout the postoperative course.

\section{Discussion}

This patient presented with retractive breathing, stridor, and decreased $\mathrm{SpO}_{2}$ immediately after extubation. We suspected that these symptoms were attributable to bronchospasm or laryngospasm associated with administration of sugammadex. It has been reported that sugammadex may cause bronchospasm [3]. This is reportedly more likely in patients with a history of respiratory disease, such as bronchial asthma. Meanwhile, bronchospasm is triggered by various mechanical (e.g., endotracheal intubation), chemical, and pharmacological stimuli. While its intraoperative respiratory adverse event is approximately $1.7 \%$, bronchospasm and laryngospasm are complications in which deaths have been reported in some severe cases [5-7]. The most common pathological condition recognized as bronchospasm is asthma. When considering the treatment for bronchospasm, volatile anesthetic agents are useful because with the exception of desflurane, they have a bronchodilator effect [8]. Desflurane increases airway resistance at a high alveolar concentration [8]. When bronchospasm is severe, it is difficult to use volatile anesthetic agents. Propofol relaxes the airway reflex [9]. Beta-stimulants, such as salbutamol and epinephrine, can also be administered intravenously [10]. Anticholinergic drugs, such as tiotropium bromide, block parasympathetic constriction of bronchial smooth muscle [11]. Intravenous magnesium sulfate is also effective for bronchospasm [12].

Laryngospasm is defined as glottis narrowing caused by reflective contraction of the laryngeal muscles. It is classified into complete and incomplete types. The complete type is referred to as a condition in which the immobility of the back leads to complete failure of ventilation, whereas the incomplete type is referred to as a condition in which the motion of the thorax is accompanied by inspiratory stridor and limited motion of the back. When incomplete laryngospasm progresses to the complete type, inspiratory stridor disappears [13, 14]. Laryngospasm frequently occurs in ambulatory anesthesia [15], while its occurrence has also been reported during orthopedic surgery $[16,17]$, laparotomy [16], and craniotomy [18]. Laryngospasm is more common in young people than in adults. In fact, its incidence has been reported to reach $14 \%$ in those aged less than 6 years [19]. A definitive diagnosis of this condition is made by examination of the vocal cords with a bronchial fiberscope [20]. When laryngospasm is diagnosed, the irritating stimulus by any triggering factor should be



Fig. 1 Changes in end-tidal carbon dioxide and arterial oxygen saturation of pulse oxymetry after sugammadex administration. Event: (1) intravenous injection of sugammadex, (2) extubation, (3) disappearance of end-tidal carbon dioxide (EtCO2), (4) decline of arterial oxygen saturation, (5) start of continuous positive airway pressure 
removed. Positive-pressure ventilation with 100\% oxygen, which forces the chin forward with strong pressure from behind the ascending rami of the jaw, is required for laryngospasm [21]. When this fails, endotracheal intubation is required. Anesthesia should be deepened with an intravenous anesthetic. For endotracheal intubation, succinylcholine is widely used as a muscle relaxant [21]. It has been reported that succinylcholine is administered to avoid significant hypoxia in approximately 25 to $50 \%$ of these cases [22]. If it is difficult to intubate using an endotracheal tube, cricothyroidotomy or tracheotomy is needed to access the airway rapidly [23]. Prolonged laryngospasm may cause serious complications, such as cardiac arrest, aspiration, and negative pressure pulmonary edema [23]. Bronchospasm and laryngospasm should be differentiated soon after onset because they differ in terms of treatment strategies and subsequent complications.

In our case, a capnometer was useful for differentiating between bronchospasm and laryngospasm. Although a definitive diagnosis of laryngospasm is made by examination of the vocal cords with a bronchial fiberscope [20], there was insufficient time to perform bronchial fiberscopy in order to prevent progression to NPPE. No waveform appears in capnometer readings of laryngospasm, which causes complete occlusion of the upper respiratory tract; however, they reveal waveform patterns of occlusive respiratory disorders and provide $\mathrm{EtCO}_{2}$ values in most cases of bronchospasm. In our case, laryngospasm was diagnosed because $\mathrm{EtCO}_{2}$ waveforms were absent on the capnometer readings, and continuous positive airway pressure with $100 \%$ oxygen was applied through a facemask, resulting in relief of symptoms.

Because there are reported cases of NPPE that occurred a few hours after extubation [24], adequate follow-up is necessary. However, our patient presented with neither subjective symptoms nor abnormal radiographic findings after surgery.

\section{Conclusions}

After extubation in this case, we detected upper airway obstruction that was presumably attributable to administration of sugammadex. The treatment strategies for upper airway obstruction vary depending on the cause. The use of a capnometer facilitated the diagnosis of laryngospasm and allowed us to administer appropriate treatment.

\section{Authors' contributions}

KK and TO collected the data and drafted the manuscript. SW and SS revised the manuscript. All authors read and approved the final manuscript.

\section{Consent for publication}

Written informed consent was obtained from the patient and his family to publish this case report and accompanying images.

\section{Competing interests}

The authors declare that they have no competing interests.

\section{Publisher's Note}

Springer Nature remains neutral with regard to jurisdictional claims in published maps and institutional affiliations.

Received: 1 May 2017 Accepted: 7 August 2017

Published online: 15 August 2017

References

1. Takazawa T, Mitsuhata H, Mertes PM. Sugammadex and rocuroniuminduced anaphylaxis. J Anesth. 2016;30:290-7.

2. Komasawa N, Nishihara I, Minami T. Relationship between timing of sugammadex administration and development of laryngospasm during recovery from anaesthesia when using supraglottic devices: a randomised clinical study. Eur J Anaesthesiol. 2016;33:691-2.

3. Amao R, Zornow MH, Cowan RM, Cheng DC, Morte JB, Allard MW. Use of sugammadex in patients with a history of pulmonary disease. J Clin Anesth. 2012:24:289-97.

4. Yoshioka N, Hanazaki M, Fujita Y, Nakatsuka H, Katayama H, Chiba Y. Effect of sugammadex on bronchial smooth muscle function in rats. J Smooth Muscle Res. 2012;48:59-64.

5. Woods BD, Sladen RN. Perioperative considerations for the patient with asthma and bronchospasm. Br J Anaesth. 2009;103(Suppl 1):i57-65.

6. Lauer R, Vadi M, Mason L. Anaesthetic management of the child with coexisting pulmonary disease. Br J Anaesth. 2012;109(Suppl 1):i47-59.

7. Subramanyam R, Yeramaneni S, Hossain MM, Anneken AM, Varughese AM. Periopetative respiratory adverse events in pediatric ambulatory anesthesia: development and validation of a risk prediction tool. Anesth Analg. 2016;122:1578-85.

8. Dikmen Y, Eminoglu E, Salihoglu Z, Demiroluk S. Pulmonary mechanics during isoflurane, sevoflurane and desflurane anaesthesia. Anaesthesia. 2003;58:745-8.

9. Eikermann $M$, Malhotra A, Fassbender P, Zaremba S, Jordan AS, Gautam S, White DP, Chamberlin NL. Differential effects of isoflurane and propofol on upper airway dilator muscle activity and breathing. Anesthesiology. 2008;108:897-906

10. Pleasants RA. Review of guidelines and the literature in the treatment of acute bronchospasm in chronic obstructive pulmonary disease. Pharmacotherapy. 2006;26:156S-63S.

11. Hvizdos KM, Goa KL. Tiotropium bromide. Drugs. 2002;62:1195-203.

12. Rowe BH, Camargo CA Jr. The role of magnesium sulfate in the acute and chronic management of asthma. Curr Opin Pulm Med. 2008;14:70-6.

13. Hartley M, Vaughan RS. Problems associated with tracheal extubation. British Anaesth. 1993;71:561-8.

14. Halow KD, Ford EG. Pulmonary edema following postoperative laryngospasm. A case report and review of the literature. Am Surg. 1993;59:443-7.

15. Kollef MH, Pluss J. Noncardiogenic pulmonary edema following upper airway obstruction 7 cases and review of the literature. Medicine. 1991;70:91-8.

16. Koch SM, Abramson DC, Ford M, et al. Bronchoscopic findings in postobstructive pulmonary oedema. Can J Anaesth. 1991;43:73-6.

17. Broccard AF, Liaudet L, Aubert J-D, et al. Negative pressure post-tracheal extubation alveolar hemorrhage. Anesth Analg. 2001;92:273-5.

18. Dohi S, Okubo N, Kondo Y. Pulmonary oedema after airway obstruction due to bilateral vocal cord paralysis. Can J Anaesth. 1991;38:492-5.

19. Flick RP, et al. Risk factors for laryngospasm in children during general anesthesia. Paediatr Anaesth. 2008;18:289-96.

20. Tagaito $Y$, Isono $S$, Nishino $T$. Upper airway reflexes during a combination of propofol and fentanyl anesthesia. Anesthesiology. 1998;88:1459-66.

21. Joshi GP, Desai MS, Gayer S, Vila H Jr; Society for Ambulatory Anesthesia (SAMBA). Succinylcholine for emergency airway rescue in class B ambulatory facilities: the Society for Ambulatory Anesthesia Position Statement. Anesth Analg 2017:124:1447-1449.

22. Burgoyne $\mathrm{LL}$, Anghelescu DL. Intervention steps for treating laryngospasm in pediatric patients. Paediatr Anaesth. 2008;18:297-302.

23. Bhattacharya M, Kallet RH, Ware LB, Matthay MA. Negative-pressure pulmonary edema. Chest. 2016;150:927-33.

24. Glasser SA, Siler JN. Delayed onset of laryngospasm-induced pulmonary edema in the adult outpatient. Anesthesiology. 1985;62:370-1. 